\title{
Discovering and Interpreting Meaning in Finnish and American Codes of Communication
}

\author{
Michael Berry \\ Turku School of Economics \\ and Business Administra- \\ tion, Finland
}

\author{
Donal Carbaugh \\ University of Massachusetts at \\ Amherst, USA
}

carbaugh@comm.umass.edu

\author{
Marjatta Nurmikari- \\ Berry \\ Turku Polytechnic, \\ Finland
}

marjatta.nurmikariberry@turkuamk.fi

\section{Abstract}

Information technologies bring into view not only ideas and their transmission via electronic devices, but also means of expression and the meanings they assume for readers / listeners / viewers. This transformation -- from information through technology to expressions and their meanings -- is an intrinsic part of any electronically mediated communication. This project explores one such electronically mediated text, Tango Finlandia, a segment of the popular American news program, 60 Minutes, as it has been broadcast and discussed prominently in the United States and Finland. Analyses of exchanges between Finnish and American students demonstrate how the "exact same" televisual information and the "exact same" English words convey information that is transformed into two different expressive systems with very different cultural meanings.

Key words : Pedagogy, Cultural Discourse, English, information technology, intercultural communication, Finland, United States, Tango Finlandia

\section{Introduction}

Information technologies bring into view not only ideas and their transmission via electronic devices, but also means of expression and the meanings they assume for readers/listeners/viewers. This transformation -- from information through technology to expressions and their meanings -- is an intrinsic part of any electronically mediated communication. This project explores one such electronically mediated text, Tango Finlandia, a segment of the popular American news program, 60 Minutes, which has been broadcast in the United States and Finland. The basic plot of this segment explains the unexpected existence of Tango in a Nordic country that champions "silence." The implicit contrast between Tango and quietude, and between silence in Finland and speaking in the US, provides the main drama for the segment. The primary data for the study, which have been gathered during the past decade in Finland and the United States, include (1) written and spoken reactions to the video clip, (2) observations of audiences viewing the clip, and (3) observations of audiences viewing the clip without any sound (the latter being productive as a result of our preliminary analyses).

Material published as part of these proceedings, either on-line or in print, is copyrighted by Informing Science. Permission to make digital or paper copy of part or all of these works for personal or classroom use is granted without fee provided that the copies are not made or distributed for profit or commercial advantage AND that copies 1) bear this notice in full and 2) give the full citation on the first page. It is permissible to abstract these works so long as credit is given. To copy in all other cases or to republish or to post on a server or to redistribute to lists requires specific permission from the publisher at Publisher@InformingScience.org
These initial data produced by Finnish and American viewers have created materials for intensive cross-cultural exchanges. Analyses of these exchanges demonstrate how the "exact same" televisual information and the "exact same" English words convey information that is transformed into two different expressive systems with very different cultural meanings. Implications of 
these findings are discussed for the study of information technologies as, inevitably, parts of cultural systems of expression. Highlighted through the analyses are both cultural ways of communicating information and the cultural meanings that are implicitly embedded in that information, here being demonstrated between US-American speakers of English and Finns who have a good command of English.

Our current analysis of data has a conceptual and an empirical dimension. The conceptual approach to understanding the tacit role of culture in multimedia and information technology is a nested conceptualization of cultural discourse, understood here to be a system of words, phrases, visual images, forms of action, and their meanings. We interpret meanings as saying something about action itself, social relations, emotions, and identity. Within each system of cultural discourse, we explore initially how partic ular terms and images co-occur in identifiable clusters. Next, we explore sets of clusters that create discursive themes, then sets of themes, and their semantic fields, all of which create, we argue, a cultural discourse. Our basic conceptual unit, therefore, is a whole-part relationship between a particular wordimage, and the larger expressive system of which it is a part. This approach employs a cultural theory of interpretation by focusing on the ways cultural discourse both presumes and creates knowledge about persons, actions, social relations, and feelings.

The discussion below introduces some examples of instances from our data of pedagogical development. This demonstrates the ways students and teachers alike can become aware of the role of culture in their uses of media and information technologies. The main issues we address here involves the visual and verbal portrayals of scenes, and the ways these are seen and interpreted differently. We focus in partic ular on "silence", "brooding", "dare to come/speak to you", "shy" and "melancholy" for each carries different meanings in their respective cultural landscapes. A general issue here is the reliance upon English as an international language, with a special interest in understanding how discursive formulations about cultural others implicate messages about one's cultural self. A good command of English and access to modern communication technology clearly provides opportunities for pedagogical development and communication across cultures. One of our goals is to create learning environments in which students can develop competence to discover and interpret meaning (CDIM) when communicating in English via information technologies. Finnish students often learn English with the goal of speaking like native speakers of English rather than primarily using English in multiple cultural contexts. As a result, they sometimes develop email communication styles that are effective within their own speech community but not necessarily understood by persons from other cultures. American students easily universalize their assumptions about communication in English, generally, and via email in particular. Responses to different forms of media via different forms of information technology provide opportunities to develop CDIM with sensitivity to multiple contexts.

\section{Practical Aspects of the Learning Process}

\section{Exchange Goal}

A primary pedagogical goal is the creation of a learning environment that is supportive of an evolution in participants' abilities to comprehend and explain the meanings in, for example, American and Finnish speech. In particular, after viewing Tango Finlandia, we asked viewers to move within and beyond the video clip to understand local social practices and taken-for-granted cultural premises associated with those practices. Eventually, American students learned to explain Finnish ways of communicating from a Finnish rather than an American perspective; the Finnish students learned, in turn, to explain their Finnish ways from a Finnish perspective, and to do so in English. Using English carried its challenges because it didn't always capture nuances in Finnish cultural meanings, and thus reaffirmed common American misconceptions. Helping students explore this process was our main goal. 


\section{Basic Approach}

We characterize our approach as a reflection on reflection. This is a process of discovery that involves exposure to stimulus materials such as the videotape and email messages about it, exercises designed to examine details in these materials, reflections upon personal experiences, and the creation of a portfolio. This approach helps students develop competence in the discovery and interpretation of their own and others' cultural meanings. In short, the experiences begin with spontaneous responses to Tango Finlandia and evolve towards an email exchange between Finnish and American students with a focus on the meaning of everyday cultural practices and the (English and Finnish) language being used to characterize the meanings of these practices.

\section{Core exercises at the beginning of the learning process: Students}

1. Read and discuss a neutral out-of-context exercise, consisting of statements related to social ways of communicating and being. Students eventually discover that Finns in Tango Finlandia made the statements.

2. Watch segments of a soundless version of Tango Finlandia, discuss and reflect in writing about their interpretation of what they saw.

3. Watch the entire video clip as presented on 60 Minutes, discuss, and write their interpretations of what they saw and heard.

4. Compare, discuss and write about how their responses to the out-of-context exercise, the viewing of soundless segments and the full version of Tango Finlandia modified or reinforced their interpretation of the out-of-context exercises, which students now realize is the speech of Finns in the video clip.

5. Read examples of previously produced Finnish and American conversation rules (guidelines for feasible and appropriate ways of communicating in the respective cultures), discuss, and write about the connection between the rules and the speech in Tango Finlandia.

\section{Exchange "procedures"}

1. American students send their responses to the video clip and questions to the Finnish students.

2. Finnish students discuss the American interpretations and answered their questions.

3. Finnish students received more questions from the American students who are trying to interpret the cultural meaning of the Finnish speech in the video clip.

4. Finnish students send questions to the Americans about the meanings of American speech in the video clip.

5. American students begin to focus on particular scenes in the video clip that are associated with the out-of-context exercise, and they send their interpretations, as well as additional questions, to Finnish students for suggestions and modifications.

6. Finnish students develop their ability to explain the local Finnish meanings in Finnish practices that are difficult for American students to understand. At this stage acquired knowledge about Finnish cultural practices becomes essential to the cross-cultural flow of information.

7. American students send a copy of their final essay on Finnish cultural ways of communicating, and Finnish students become aware of the some of the strategies that they had developed to help Americans students escape an American frame of reference and begin to enter a Finnish frame of reference. 


\section{Learning results}

1. American students involved in an intensive, if short email exchange, become aware of the complexity but also the possibilities of learning from the exchange with Finnish students, and they astonish the Finnish students by demonstrating the evolution in their ability to understand Finnish cultural practices from a Finnish perspective.

2. Finnish students gain insights into American practices but the main learning comes from realization that they must become aware of the taken for granted in their cultural practices and develop the ability to use English in a way that non-Finns can understand the "natural" Finnish way to be from a Finnish perspective.

\section{Dealing with Three Salient Contexts}

The learning experience involves three salient contexts: American culture, Finnish culture, and the Tango media context. By getting Finnish comments, one can add to the Tango context, and when American students become aware of taken-for-granted American assumptions, they become aware of the cultural dimension in media manipulation: how media turns strangers upside down so that locals (USAmerican viewers) "understand" strangers or at least feel good about themselves.

A fundamental challenge is development of awareness of the need to focus on how Finnish quietude can be full of meanings. This suggests multiple dimension of non-verbal communication that comes from observation of the environment and the people in it. With the exception of Finnish cinema students, very few Finnish and American students are aware of this challenge prior to the learning experience. Fundamental questions also remain after the initial learning experience: what forms of media and IT communication help us have a more holistic approach to the communication process. To what extent do dimensions of personal, professional and cultural frames of reference influence our use of "neutral" technical forms of communication -- both at the visual level and the level of human ways of communicating, which can be non- verbal and verbal in an international language.

\section{Two Aspects of the Learning Process}

We briefly introduce two aspects of the learning process below:

1. Evolution in the interpretation of Finnish ways of being and speaking in the out-of-context exercise, the soundless version of segments of Tango Finlandia, and the broadcasted version of Tango Finlandia

American students and Finnish business students tend to move in a negative direction as they go through this process. The American students simply hear American media interpretations of a highly respective "news" program that make sense, given the reputation of 60 Minutes, American cultural practices, and the students' assumptions about appropriate communication. The Finnish business students want Finns to be more open and are concerned about negative images of Finns abroad. In contrast, Finnish cinema students focus on the technical aspects of the video clip. They immediately detect (1) the video's manipulations of images to reinforce negative American descriptions of Finns and (2) the non-verbal communication of Finns who send a message of humor in their speech. They easily distinguish between the positive, if exaggerated and humorous, speech of the Finns and the editing strategies of 60 Minutes that turn humor into "facts", sending an American message about Finns to Americans. If other Finnish students tend to require a little more time to view the video again and reflect, American students require considerably more time, successful only when reinforced by Finnish explanations.

2. Finnish cultural responses to American questions and interpretations of Finnish communication 
The initial American reactions to Tango Finlandia include the following words that one group used to describe Finns: cold (3 times), depressed/sad/unhappy (9 times), lifeless, impersonal (2), emotionless (5), serious (3), private (2), shy (5), rude (2), unfriendly (2), lonely, miserable. When the American teacher asked for observations about the list, a girl said, "they're all negative." The teacher mentioned that he had not asked for negative terms, so "why is this list negative?" Another student said, "they're not like us, so we see them that way." The teacher then observed, "so not like us means something negative?" And the students were "stuck."

Students began to send observations and questions to Finnish students and the process of becoming "unstuck" gradually began to take place, especially for those students who participated in email exchange with Finnish students. The examples of Finnish responses to American perplexity represent only the tip of the data currently being analyzed by the research team that includes Lu Anne Carbaugh in addition to the authors. Each statement contained terminology, and the images associated with it, that sent negative messages to most American viewers.

Example 1: a local man explaining Finnish ways of communicating.

"We're a silent, brooding people we think a lot. We like to keep our privacy and give the fellow man his privacy -- keep a distance."

Finnish student's reply to questions about example 1: "My interpretation for Knutas [the local man] saying that Finns are "silent, brooding people" is that we are quiet and comfortable with quietness. Having our own privacy is important to us and there are moments when a Finn wants to be in his/her own thoughts and that is not seen as a problem in Finland and it is not supposed to have a negative connotation."

Examples 2 \& 3: a local woman describes how a person approaches other people and an American commentator makes an observation to which a local person replies.

Example 2: a local woman describes how a person approaches other people.

"We have like a wall here. We try to look at you and watch who you are -- what you are before we dare to come to you and speak with you and I guess the American people are more like $\boldsymbol{h i}$-who are you. Where are you from? Nice meeting you. I love you."

Example 3: an American commentator makes an observation and a local person replies.

The American commentator says: it strikes me traveling around this country that people are terribly shy particularly the men.

The local person replies: among ourselves, we think that is the natural way to be, not to sort of stick out. It's easy to see that from coming from another country you think of it as shyness, and it probably is yes.

Finnish student: "my interpretation for example 2 and example 3 would be that we (Finns) want to protect ourselves from the unknown but we also want to protect the other person from the unknown. We want to respect the other person's privacy and in a way make sure that he/she really wants to talk. In Finland it's ok not to talk all the time and in my opinion most of the Finns don't feel awkward when nobody talks. We don't feel that we have to talk just for talking (in order to avoid silence) and we can feel comfortable when nobody is talking, we are comfortable with quietness."

Example 4: a local man talks about the lyrics of tango songs in his country.

The local person says: Lyrics is very important because the stories are quite sad and melancholy stories, and they are they are necessary to [our] people. 
The American asks: why this sadness?

The local man replies: because we are very melancholy people here in [our country] and we need that.

Finnish student: In [example 4] my interpretation for "melancholy" is that it doesn't really mean pessimism. It might mean sadness (e.g. after a loss) but in my opinion melancholy could also be ne utral or even positive. Melancholy might mean that a person is longing for something (something that he/she won't necessarily ever have) but it doesn't mean that melancholy plays a great role in his/her life. Melancholy is something that is there but it doesn't make us pessimistic and it doesn't mean that we pity ourselves all the time.

\section{Student Produced Conclusions}

At the end of this complex process of being misled by but also enabled by different forms of media and information technology, many American students who were unable to participate in the email exchange remain perplexed about Finnish mentality and social practices, even though the Finnish email information had been shared with them via the teachers in the course, which consisted of over 300 students at the American university. In contrast, the small group of American students who participated in an email exchange with the Finnish students were able to develop the ir ability to discover and interpret some of the Finnish cultural meanings hidden from them when first viewing Tango Finlandia.

As a final American essay by email correspondents put it,

"Our exchange with Finnish students has brought new insight on our perspective of Finnish culture. When we first viewed "Tango Finlandia" we had a skewed vision of what Finnish culture was like .... After exchanging e-mail with our Finnish counterparts, our understanding of Finnish culture and in particular, the cultural rules and premises related to the expression of love, was clarified. We have a clearer understanding of a portion of the Finnish culture and have also been able to deduce certain premises in a small part of the American culture. Our better understanding of the way in which the Finnish people live, gives us, as Americans, a better sense of the way we exist. Ultimately our work this semester, focusing on the Finnish communication patterns, has helped us to realize and accept that one culture is not right nor wrong; just different."

When the Finnish students read this final essay, a typical Finnish response is:

"After reading the American final essay I realised that the American students' evolution in the development to understand Finnish communication was actually pretty amazing. During the course they were open-minded enough in trying to explore Finnish communication and the cultural codes within it. They analysed Tango Finlandia very carefully and despite of the American narrator they were able to criticise the stereotypes that the video presents. I was also very glad after noticing that the American students were able to present their explanations about Finnish communication in a positive way. They combined the information they received from different channels and I have to say that I am very impressed.

I also noticed some development in my own abilities to explain Finnish meanings. As I mentioned earlier in the text it is very difficult to explain things that you take for granted. Analysing Tango Finlandia and [ex]changing views with exchange students and American students during the course helped me to explain Finnish meanings. I still consider the task very difficult yet rewarding. Reading the American final essay also helped me in this challenging task. I am glad that I was able to help the Americans to understand Finnish communication but I was also happy to realise that with their contribution I was able to understand my own culture better." 


\section{References}

(The references listed below have provided the theoretical and practical basis for an ongoing pedagogical development and analysis of student produced data.)

Berry, M. (1999). Discovering and interpreting cultural meaning. In D. Killick and M. Parry (eds) Promoting the Discipline: Marking Boundaries \& Crossing Borders. Proceedings of the conference Cross-Cultural Capability (pp. 1-18). Leeds, UK: Leeds Metropolitan University.

Berry, M. (1999). Developing a multicultural E-mail network. In K Knapp, B. Kappel, K Eubel-Kasper \& L. Salo-Lee (eds.) Meeting the Intercultural Challenge. Verlag Wissenschaft \& Praxis:Sternenfels, pp. 381-388.

Berry, M. (1999). Reflections on reflections. Integrating pedagogical and research agendas to meet the intercultural challenge. In K. Knapp, B. Kappel, K. Eubel-Kasper and L. Salo-Lee (eds) Meeting the Intercultural Challenge (pp.312319). Verlag Wissenschaft \& Praxis: Sternenfels.

Berry, M. (1998). Reflections on learning from exchange students in Finland and Austria. In K. Häkkinen, (ed) Multicultural Education. Reflection on Theory and Practice (pp. 172-181). Jyväskylä, Finland: University of Jyväskylä.

Berry, M. (1998). Reflections on learning from students in a multicultural learning environment. In D. Killick and M. Parry (eds) The Why, the Ways \& The Means: New Theories \& Methodologies in Language Education. Proceedings of the conference Cross-Cultural Capability (pp. 56-63). Leeds, UK: Leeds Metropolitan University.

Berry, M. (1997). Speaking culturally about personhood, motherhood and career. In I. Aaltio-Marjosola and G. Sevon (eds) Gendering organization topics. Hallinnon tutkimus [Administrative Studies] 4, 304-325.

Berry, M., Carbaugh, D. \& Nurmikari-Berry, M. (under review). Communicating Finnish comfort with quietude to those uncomfortable with silence.

Berry, M. \& Markowski, K. (2002). Discovering cultural meaning via email \& a common foreign language. A FinnishFrench experience in multiple third spaces. In S. Cormeraie, D. Killick, and M. Parry (eds) Revolutions in Consciousness: Local Identities, Global Concerns in 'Language and Intercultural Communication'. Proceedings of the First IALIC ConferenceConference (pp. 229-237). Leeds, UK: Leeds Metropolitan University.

Berry, M. \& Nurmikari-Berry, M.. (2002). Awareness of false friends in multiple third spaces. Poster presentation. EUROCALL 2002 Conference: Networked language learning - a link missing? Jyväskylä, 14-17 August 2002

Berry, M. \& Nurmikari-Berry, M. (1998). Pedagogical and institutional challenges to teaching foreign languages and intercultural communication. Projekti. (Turun Kauppakorkeakoulun Tutkijoiden ja Jatko-Opiskelijoiden Tiedotuslehti)(vol 1, pp.6-8) Turku, Finland: Turku School of Economics and Business Administration.

Block, D. \& Cameron, D. (eds). (2002). Globalization and language teaching. London: Routledge.

Carbaugh, D. (1996). Situating selves: the communication of social identities in American scenes. Albany, NY: State University of New York Press.

Carbaugh, D. (1995). Are Americans really superficial?: Notes on Finnish and American cultures in linguistic action. In Liisa Lalo-Lee (ed) Kieli \& kulttuuri oppimisessa [Language and culture in teaching and learning] (pp. 53-60). Jyväskylä, Finland: Department of Communication, University of Jyväskylä.

Carbaugh, D. (1993). "Soul" and "self": Soviet and American cultures in conversation. Quarterly Journal of Speech 79, 182200.

Carbaugh, D. (ed) (1990). Cultural communication and intercultural contact. Hillsdale, NJ: Lawrence Erlbaum Associates.

Carbaugh, D. \& Berry, M. (2001). Communicating history, Finnish and American discourses: An ethnographic contribution to intercultural communication inquiry. Communication Theory 11(3), 352-366.

Carbaugh, D. \& Hastings, S. (1992). A role for communication theory in ethnography and cultural analysis. Communication Theory, 2, 156-165.

Carbaugh, D. \& Poutiainen, S. (2000). By way of introduction: An American and Finnish dialogue. In M. Lustig and J. Koester (eds) Among US: Essays on Identity, Belonging, and Intercultural Competence (pp. 203-212), New York: Addison Wesley Longman.

Hawisher, G. \& Selfe, C. (eds) (2000). Global Literacies and the World-Wide Web. Routledge: London.

Hymes, D. (1996). Ethnography, linguistics, narrative inequality: Toward an understanding of voice. London: Taylor and Francis. 
Hymes, D. (1972). On communicative competence. In J. Pride and J. Holmes (eds) Sociolinguistics (pp.269-93). Harmondsworth: Penguin.

Hymes, D. (1972). Models of the interaction of language and social life. In J. Gumperz and D. Hymes (eds) Directions in sociolingjuistics: The ethnography of communication (pp.35-71). New York: Holt, Rinehart, and Winston.

Kramsch, C. (2000). Context and culture in language teaching. Oxford: Oxford University Press.

Kramsch, C. \& Thorne, S. (2002). Foreign language learning as global communicative practice. In D. Block and D. Ca meron (eds) Globalization and Language Teaching (pp. 83-100). London: Routledge.

Lehtonen, M. (2000). The cultural analysis of texts. Sage: London.

Nurmikari-Berry, M. \& Berry, M. (1999). Discovering cultural meanings as the first step towards developing intercultural communication competence. In K. Häkkinen (ed) Innovative Approaches to Intercultural Education. (pp.109-119). Jyväskylä, Finland: University of Jyväskylä.

R. O'Dowd. (2000). Intercultural learning via videoconferencing: a pilot exchange project, ReCALL 12 (1), pp.49-61.

Philipsen, G. (1992). Speaking culturally. Explorations in social communication. Albany: State University of New York Press.

Roberts, C., Byram, M., Barro, A., Jordan, S. \& Street, B. (2001). Language learners as ethnographers. Clevedon: Multilingual Matters.

Saijavaara, I. \& Lehtonen, J. (1997). The silent Finn revisited. In A. Jaworski (ed) Silence Interdisciplinary Perspectives (pp. 263-283). Berlin: Mouton de Gruyter.

\section{Biographies}

Michael Berry moved to Finland as a Fulbright professor of history and international relations in 1975. He is currently a senior lecturer in English and a docent (adjunct professor) in Intercultural Relations at the Turku School of Economics and Business Administration as well as a docent in history at the Universities of Turku and Tampere. Berry has also been a visiting professor of Intercultural Communication and Management at Johannes Kepler University since 1996. His research focuses on interdisciplinary pedagogical development that brings together multiple dimensions of history in contemporary speech and communication across cultures via IT technology and English as an international language.

Donal Carbaugh is Professor of Communication at the Unive rsity of Massachusetts at Amherst, author of Cultures in Conversation Situating Selves: The Communication of Social Identities in American

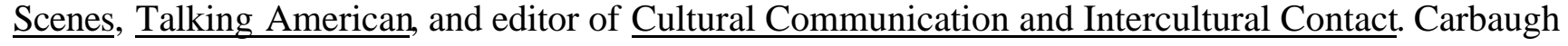
has been actively involved in researching Finnish communication since his Fulbright professorship in Finland in 1992.

Marjatta Nurmikari-Berry is a lecturer of English and Communication at the Turku Polytechnic. She has been actively involved in the development of pedagogical approaches to discovering and interpreting cultural meaning from a regional Finnish perspective, primarily working with Finnish students with multiple regional and professional interests, e.g. design, sustainable development, cinema students. Nurmikari-Berry has played a key role the discovery and interpretation of Finnish cultural meanings that are often initially hidden from "stranger" researchers and, indeed, Finns themselves. These insights have been developed in her courses on intercultural communication in English as an international language. 